\title{
Seismic Performance Analysis of Three-Arch Double-Deck Metro Station Based on Response Displacement Method
}

\author{
Deyun Ding ${ }^{1, a}$, Weifeng Wang $^{1}$, Meiqun Huang ${ }^{1}$, Xiuren Yang $^{1}$ and Zongzhen \\ $\mathrm{Wu}^{2}$ \\ ${ }^{1}$ Beijing Urban Engineering Design and Research Institute Co., Ltd., Beijing, 100037, China \\ ${ }^{2}$ School of Civil Engineering, Beijing Jiaotong University, Beijing, 100044, China \\ adyding2301@163.com
}

\begin{abstract}
Keywords: Three-arch double-deck metro station, Seismic performance, Response displacement method, Finite element, Reinforcement design.
\end{abstract}

\begin{abstract}
Taken the Dawanglu station of Beijing metro line 14 as engineering background, the response displacement method is used to analyze the seismic performance of the three-arch double-deck metro station modeled by the two-dimensional finite element method. Numerical results show that the seismic calculation based on the response displacement method can be used in the seismic design of metro engineering, considering the soil-structure interaction and their vibration characteristics. Under the seismic loads, the larger moment of the three-arch double-deck metro station mainly occurs on the sidewall and at the base plate near the sidewall. For the three-arch double-deck metro station, the static and seismic conditions should be taken into account in the reinforcement design of structural elements.
\end{abstract}

\section{Introduction}

As an important part of the urban lifeline engineering, the earthquake-resistance of metro engineering causes great attention [1-5]. Especially, after the Wenchuan earthquake in 2008, the seismic performance calculation of metro station structure is required in the design of metro engineering.

Calculation methods of seismic effects of underground structures include the seismic coefficient method, response displacement method, response acceleration method, elastic time-history method, nonlinear time-history method and so on [6-8]. Currently, it is suggested that the seismic coefficient method should be used in underground engineering design in China.

In this paper, the Dawanglu station of Beijing metro line 14 is taken as engineering background. The response displacement method is used to analyze the seismic performance of a three-arch double-deck metro station.

\section{Project Overview}

The main structure of the Dawanglu station is a three-arch double-deck structure, and its maximum width and height are respectively 25.3 and $15.7 \mathrm{~m}$. The overburden depth is $8.7 \mathrm{~m}$ below the ground surface, and the anti-floating water depth is $4.5 \mathrm{~m}$. The station is built by a new construction method called the top-down boring with cast-in-situ arch. The main structure is composed of arch plate, sidewall, base plate, floor plate and steel tube column, as shown in Fig.1.

For this station, the seismic fortification criterion is defined as the Category B. The seismic level is Level 3, and the seismic fortification level is 8th degree. The design seismic group is Group 1 (the site characteristic period is $0.35 \mathrm{~s}$ ), and the design ground motion acceleration is $0.2 \mathrm{~g}$.

\section{Response Displacement Method}

When the response displacement method is used in the calculation of lateral seismic response of metro station structure, the surrounding soil can be regarded as the foundation springs of the support 
structure, and the beam elements are used in the structural modeling. Fig. 2 shows the loads diagram of the Dawanglu station using the response displacement method.

Soil Horizontal Displacement. According to the following formula, the horizontal displacement along the soil depth direction in earthquake can be given:

$$
U(z)=\frac{1}{3} u_{\max } \cos \left(\frac{\pi z}{2 H}\right)
$$

where $U(\mathrm{z})$ is the horizontal displacement of soil at depth $z, z$ is the soil depth, $u_{\max }$ is the maximum displacement of the ground surface, $H$ is the distance from the ground surface to the soil surface in seismic design.

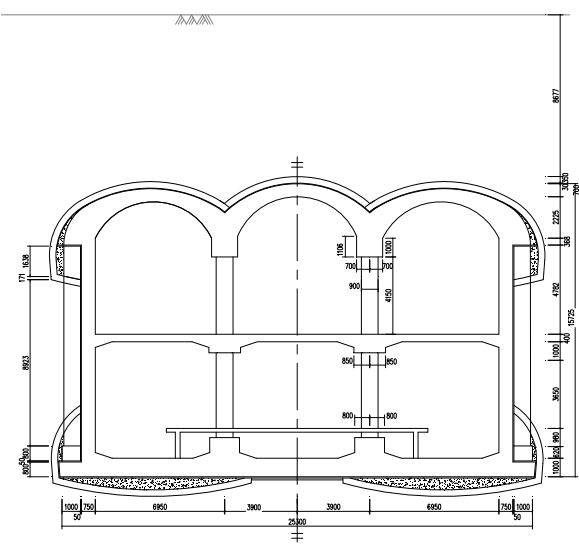

Fig. 1 Cross section of metro station

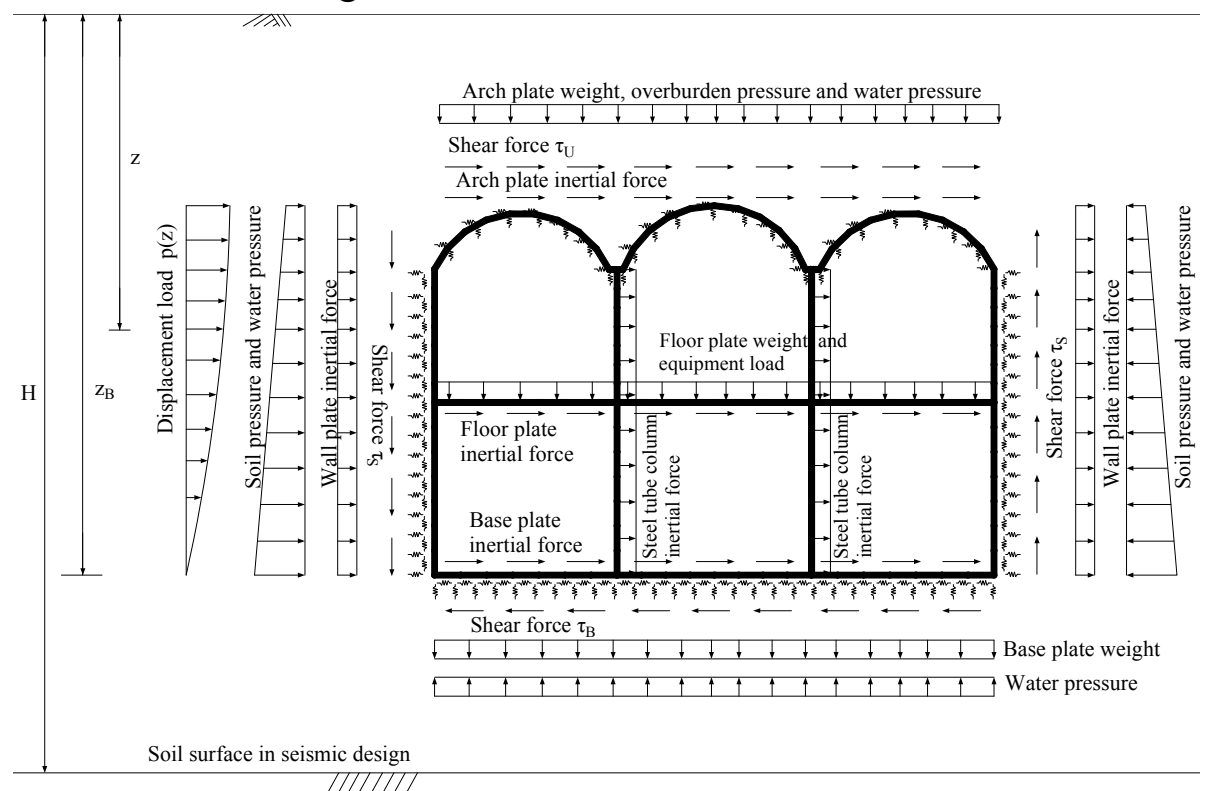

Fig. 2 Loads diagram of the Dawanglu station

Displacement Load. The above horizontal displacement can be transferred into equivalent loads applied directly on the sidewall and arch plate of the main structure:

$p(z)=K_{\mathrm{h}}\left[U(z)-U\left(z_{\mathrm{B}}\right)\right]$

where $p(z)$ is the displacement load caused by the soil deformation, $K_{\mathrm{h}}$ is the soil horizontal spring coefficient per unit area in earthquake.

Shear Force between Structure and Soil. The shear force between the structure and soil can be calculated according to the following formula:

$$
\begin{gathered}
\tau_{\mathrm{U}}=\frac{G_{\mathrm{d}} T_{\mathrm{g}}^{2} S_{\mathrm{a}}}{2 \pi^{2} H} \sin \left(\frac{\pi z_{\mathrm{U}}}{2 H}\right) \\
\tau_{\mathrm{B}}=\frac{G_{\mathrm{d}} T_{\mathrm{g}}^{2} S_{\mathrm{a}}}{2 \pi^{2} H} \sin \left(\frac{\pi z_{\mathrm{B}}}{2 H}\right)
\end{gathered}
$$




$$
\tau_{\mathrm{S}}=\frac{\tau_{\mathrm{U}}+\tau_{\mathrm{B}}}{2}
$$

where $\tau_{\mathrm{U}}$ is the shear force of the upper surface of arch plate, $\tau_{\mathrm{B}}$ is the shear force of the lower surface of base plate, $\tau_{\mathrm{S}}$ is the surface shear force of the sidewall, $G_{\mathrm{d}}$ is the dynamic shear modulus of soil, $T_{\mathrm{g}}$ is the characteristic period value of soil, $S_{\mathrm{a}}$ is the surface acceleration response spectrum.

Structural Inertial Force. The inertial force of the main structure can be expressed by the mass of the structures multiplied by the maximum acceleration. It can be regarded that the concentrated force is applied on the structural centroid, or regarded as the lateral inertial force calculated by the maximum acceleration of each parts applied on corresponding parts. The calculation formula is as follows:

$$
f_{i}=m_{i} \ddot{u}_{i}
$$

where $f_{i}$ is the inertial force of the element $i, m_{i}$ is the mass of the element $i, \ddot{u}_{i}$ is the peak acceleration at the position of the element $i$.

Spring Stiffness between Soil and Structure. The soil surrounding the structure is modeled by the foundation spring including compression spring and shear spring. The stiffness of the springs is calculated according to the following formula:

$k=K L d$

where $k$ is the stiffness of compression spring and shear spring, $K$ is the foundation reaction force coefficient, $L$ is the foundation spring spacing, $d$ is the calculated length of soil along the longitudinal direction of metro station.

\section{Two-Dimensional Finite Element Model and Parameters}

A two-dimension finite element model is established by choosing the central line of structural members. In the model, the thickness of the arch plate, floor plate, base plate and sidewall are respectively $0.7,0.4,1$ and $0.75 \mathrm{~m}$. Steel tube column is approximately simulated by transferring its circular cross-section into rectangular cross-section by the equivalent bending stiffness method, and its equivalent thickness is $0.072 \mathrm{~m}$.

By means of putting the parameters in Table 1 into the Equations $(1) \sim(7)$, the value of loads and spring stiffness in the model can be obtained. The maximum of relative horizontal displacement is $7.59 \mathrm{~mm}$ at the arch plate, and the corresponding lateral displacement load $p(z)$ is $345 \mathrm{kN} / \mathrm{m}^{2}$.

Table 1 Parameter values

\begin{tabular}{|l|c|c|}
\hline \multicolumn{1}{|c|}{ Type } & Value & Unit \\
\hline Weighted density of soil above base plate $\rho$ & 19.93 & $\mathrm{kN} / \mathrm{m}^{3}$ \\
\hline Weighted coefficient of earth pressure at rest above base plate $K_{0}$ & 0.387 & - \\
\hline Weighted vertical coefficient of subgrade above base plate $K_{\mathrm{v}}$ & 43.9 & $\mathrm{MPa} / \mathrm{m}$ \\
\hline Weighted horizontal coefficient of subgrade above base plate $K_{\mathrm{h}}$ & 45.5 & $\mathrm{MPa} / \mathrm{m}$ \\
\hline Dynamic shear modulus of soil above base plate $G_{\mathrm{d}}$ & 163.3 & $\mathrm{MPa}$ \\
\hline Characteristic period value of soil layers $T_{\mathrm{g}}$ & 0.35 & $\mathrm{~s}$ \\
\hline Peak acceleration of ground motion $S_{\mathrm{a}}$ & 2 & $\mathrm{~m} / \mathrm{s}^{2}$ \\
\hline Maximum surface displacement $u_{\max }$ & 0.13 & $\mathrm{~m}$ \\
\hline Distance from ground surface to the soil surface in seismic design $H$ & 60 & $\mathrm{~m}$ \\
\hline Peak acceleration $\ddot{u}_{i}$ & 2 & $\mathrm{~m} / \mathrm{s}^{2}$ \\
\hline Equipment load & 8 & $\mathrm{kN} / \mathrm{m}$ \\
\hline
\end{tabular}

\section{Numerical Result Analysis}


Axial Force, Shear Force and Moment of Main Structure. Fig.3 shows the axial force, shear force and moment diagram of the main structure. The axial force distributes asymmetrically, and all structural members are in the state of axial compression. The maximum axial force is at the right side of floor plate, and the value is $3327 \mathrm{kN}$. The shear force also distributes asymmetrically. The maximum shear force is at the left sidewall near the floor plate, and its value is $1813 \mathrm{kN}$. The moment distributes asymmetrically. The maximum moment is at the base plate near the left sidewall, and its value is $2568 \mathrm{kN} \cdot \mathrm{m}$

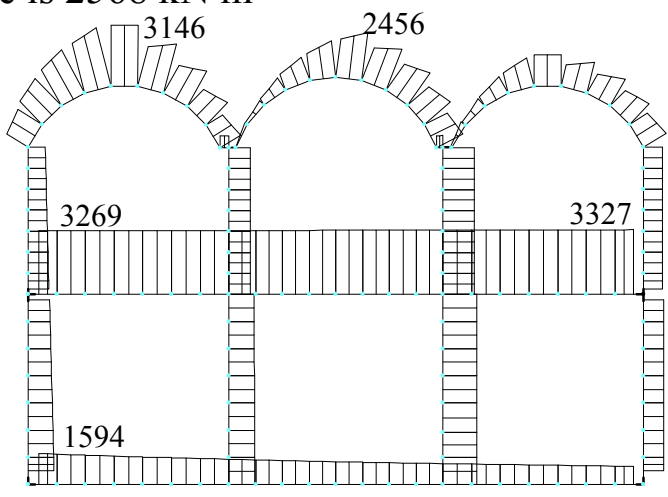

(a) Axial force (Unit: $\mathrm{kN}$ )

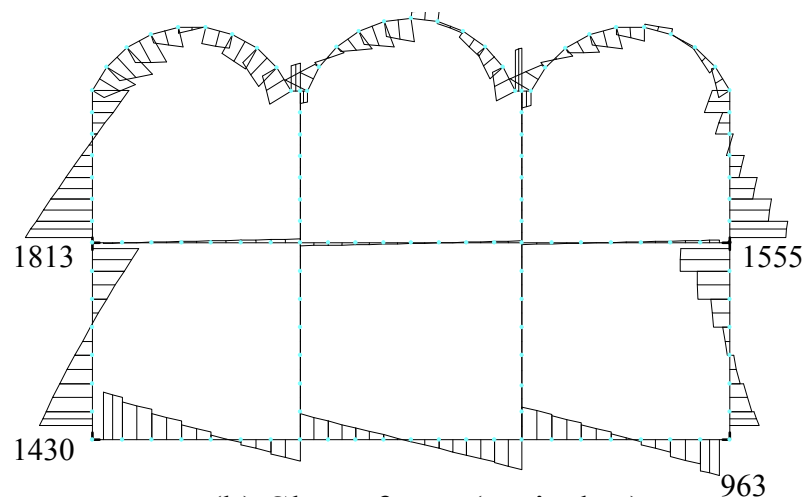

(b) Shear force (Unit: $\mathrm{kN}$ )

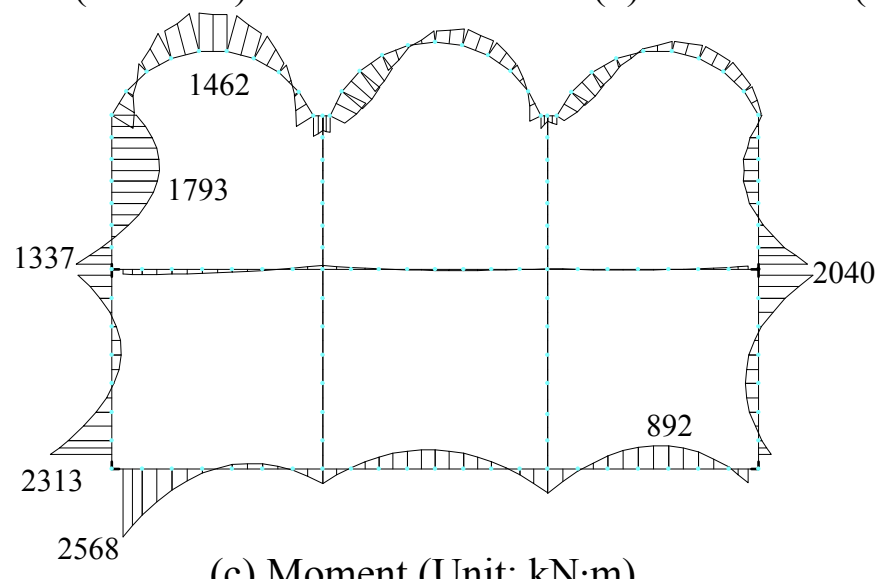

(c) Moment (Unit: $\mathrm{kN} \cdot \mathrm{m}$ )

Fig. 3 Axial force, shear force and moment diagram of the main structure

Internal Force and Reinforcement of Control Sections. Several control sections (Fig.4) of the main structure are chosen to do the reinforcement design. According to the Code for seismic design of buildings (GB50011-2010), when the loads combination is considered in the seismic condition, the design value should be adjusted by the bearing capacity seismic adjustment coefficient $\gamma_{\mathrm{RE}}$. In this paper, the value of $\gamma_{\mathrm{RE}}$ is 0.85 . Under the seismic condition, the structural members are regarded as eccentrically compressed members.

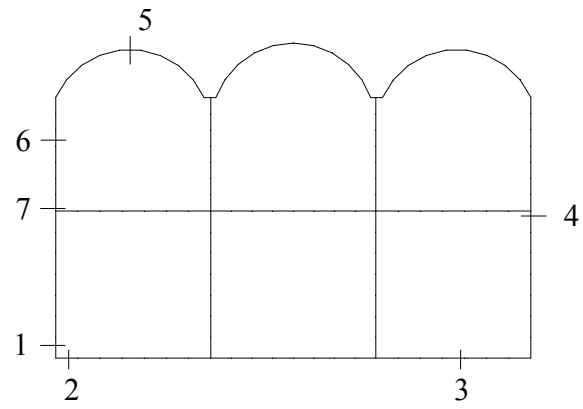

Fig. 4 Observation cross-section

Table 2 shows the internal force and reinforcement design of 7 control sections. It can be clear that under seismic loads, the comparatively large moment appears on the sidewall and the base plate near the sidewall. Except for the section 4, the reinforcement of other sections is controlled by the static conditions, in other word, the reinforcement is not controlled by the seismic condition. 
Table 2 Internal force and reinforcement of control sections

\begin{tabular}{|c|c|c|c|c|c|c|}
\hline \multirow{2}{*}{ Section No. Size $(\mathrm{mm} \times \mathrm{mm})$} & \multicolumn{3}{|c|}{ Internal force } & \multicolumn{2}{c|}{ Area of reinforcement $\left(\mathrm{mm}^{2}\right)$} \\
\cline { 3 - 7 } & & Axial $(\mathrm{kN})$ & Shear $(\mathrm{kN})$ & Moment $(\mathrm{kN} \cdot \mathrm{m})$ & Seismic condition & Static condition \\
\hline 1 & $750 \times 1000$ & 1340 & 1430 & 2313 & 9027 & 12315 \\
\hline 2 & $1000 \times 1000$ & 1593 & 1286 & 2568 & 6274 & 12315 \\
\hline 3 & $1000 \times 1000$ & 1002 & 42 & 892 & 2000 & 6158 \\
\hline 4 & $750 \times 1000$ & 1036 & 1325 & 2040 & 8133 & 6158 \\
\hline 5 & $700 \times 1000$ & 3135 & 155 & 1462 & 3657 & 6158 \\
\hline 6 & $750 \times 1000$ & 954 & 86 & 1793 & 7097 & 12315 \\
\hline 7 & $750 \times 1000$ & 1074 & 1812 & 1337 & 4861 & 6158 \\
\hline
\end{tabular}

\section{Conclusions}

In this paper, the response displacement method is used to analyze the seismic performance of a three-arch double-deck metro station. Conclusions are as follows:

1) The seismic calculation based on the response displacement method can be used in the seismic design of metro engineering, considering the soil-structure interaction and their vibration characteristics.

2) Under the seismic loads, the larger moment of the three-arch double-deck metro station mainly occurs on the sidewall and at the base plate near the sidewall.

3) For the three-arch double-deck metro station, the static and seismic conditions should be taken into account in the reinforcement design of structural elements.

\section{Acknowledgements}

This work is financially supported by the National Key Technology Research and Development Program of the Ministry of Science and Technology of the People's Republic of China (Grant No.2012BAJ01B01) and the Technology Innovation Project of Beijing Urban Engineering Design and Research Institute Co., Ltd. (Grant No. 2011-28).

\section{References}

[1] S. Samata, H. Ohuchi and T. Matsuda: Cement and Concrete Composites, Vol. 19 (3) (1997), p. 223.

[2] Jingbo Liu and Bin Li: China Civil Engineering Journal, Vol. 39(6) (2006), p. 106.

[3] Hong Xu, Dengbang Lu, Xiaoliang Yu and Xiuxin Wang: Jiangsu Construction, Vol. 1 (2008), p. 26.

[4] Yu'e Zhang, Baohong Bai, Yaohui Zhang and Zanzhi Wang: Journal of Vibration and Shock, Vol. 22(1) (2003), p. 70.

[5] Lin Song, Zhaobo Meng, Minzhe Wu and Jun Yuan: World Earthquake Engineering, Vol. 26(2) (2010), p.187.

[6] Chuan He and Atsushi Koizumi: Structural Engineering and Mechanics, Vol. 11(6) (2001), p. 651.

[7] Ministry of Housing and Urban-Rural Development of the People's Republic of China: Code for Seismic Design of Urban Rail Transit Structures, Opinion Soliciting Draft, (2010).

[8] Ministry of Housing and Urban-Rural Development of the People's Republic of China: Code for seismic design of buildings, GB50011-2010. 